Abbreviated Key Title: Sch Int J Obstet Gynec ISSN 2616-8235 (Print) |ISSN 2617-3492 (Online) Scholars Middle East Publishers, Dubai, United Arab Emirates Journal homepage: https://saudijournals.com

Original Research Article

\title{
Intrauterine Pregnancy on Intrauterine Device
}

\section{Rahmoune Mohammed*, Fdili Alaoui Fatima Zohra, Jayi Sofia, Chaara Hikmat, Melhouf My Abdelilah}

Service de Gynécologie Obstétrique 2 du CHU Hassan II à Fès, Morocco

\author{
DOI: $10.36348 /$ sijog.2021.v04i01.005
}

| Received: 08.01.2021 | Accepted: 19.01.2021 | Published: 29.01.2021

*Corresponding author: Rahmoune Mohammed

\section{Abstract}

The Intrauterine Device is a means of contraception with an efficiency of over $98 \%$. We report the case of a viable pregnancy with an IUD and the risks involved.

Keywords: Pregnancy- IUD, Intrauterine Device.

Copyright ( $) 2021$ The Author(s): This is an open-access article distributed under the terms of the Creative Commons Attribution 4.0 International License (CC BY-NC 4.0) which permits unrestricted use, distribution, and reproduction in any medium for non-commercial use provided the original author and source are credited.

\section{INTRODUCTION}

Contraception is the set of methods to prevent unwanted pregnancy. There are several methods (hormonal and non-hormonal).

The Intrauterine Device is a mechanical contraceptive method (made of copper or hormones) Its mode of action is a direct toxicity of copper on spermatozoa and endometrial inflammatory reaction. It has counter-indications (-Existing or suspected pregnancy-Current or recent upper genital infection (<03 months)-Purulent cervicitis ...) its efficiency rate is up to $98 \%$.

\section{EXPERIMENTAL SECTION}

Mrs. K.E., 30 years old, with no particular pathological history, mother of 4 children, all delivered by the vaginal route, has been wearing a copper IUD for 3 years. She presented herself in consultation for amenorrhoea of 2 months and in whom the clinical examination found an apyretic patient, a pregnant purplish cervix with an enlarged uterus of non painful size. The stitches are no longer visible, and a biological examination showed a Bhcg of $80864 \mathrm{mUI} / \mathrm{ml}$. Obstetrical ultrasound revealed a 9-week intrauterine pregnancy and the presence of an intrauterine device (IUD).

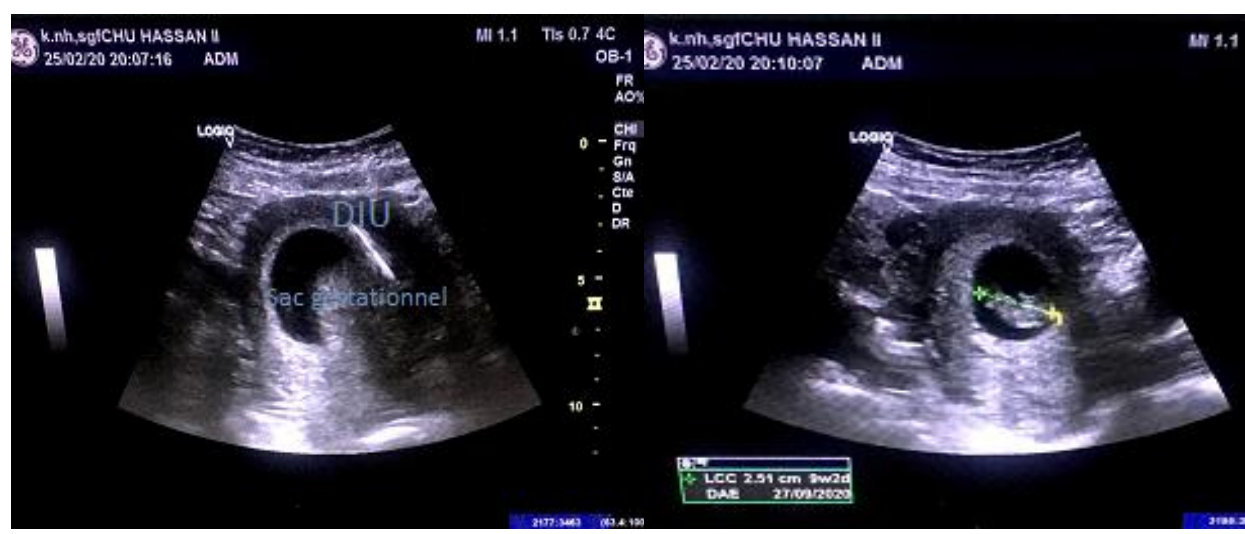

Fig-1: Presence of an IUD with a 9-week intrauterine pregnancy

\section{RESULTS AND DISCUSSION}

The Intrauterine Device or IUD is a device inserted into the uterine cavity. It provides contraception over several years (5 to 10 years depending on the model).
The IUD appears to be one of the most reliable reversible means of contraception with a failure rate of $1.1 \%$ in the first year of use [1]. 
There are 2 types: copper and hormonal.

The intrauterine pregnancy rate is between 0.8 and 3 per 100 woman-years depending on the models and series for the copper IUD. Pregnancy can be seen with an IUD in good position, but the first factor of failure is certainly the displacement (or initial bad position) of the device, hence the interest of ultrasound monitoring.

It has the following characteristics:

- A risk of early spontaneous miscarriage multiplied by 3 or 4 ;

- Spontaneous miscarriages more often late (2nd trimester) or even premature deliveries (3rd trimester);

- These late miscarriages and/or premature deliveries most often take place in infectious contexts (chorioamnionitis).

No study has been able to show a toxic, teratogenic or malformative effect linked to the presence of the copper IUD. Therefore, the discovery of an intrauterine pregnancy with an IUD requires its removal as long as the thread(s) of the intrauterine device is (are) still easily accessible.
The woman can choose to terminate the pregnancy or continue it. If she chooses to continue and the IUD is still in place, she should be monitored closely.

In our case, the woman has decided to keep the pregnancy. She is closely monitored in our hospital as a high-risk pregnancy.

\section{CONCLUSION}

The IUD is an effective means of contraception. Pregnancies with IUD are very rare. During a pregnancy with an IUD, if the mother wishes to keep it, she needs a close follow-up to avoid complications.

Acknowledgements: All authors declare having no conflict of interest in the current case report.

\section{REFERENCES}

1. Moreau, C., Trussell, J., Rodriguez, G., Bajos, N., \& Bouyer, J. (2007). Contraceptive failure rates in France: results from a population-based survey. Human Reproduction, 22(9), 2422-2427. 